\title{
Investigation of thermophysical properties of alates (swarmers) termite wing as potential raw material for insulation
}

\author{
Sunday Edet Etuk ${ }^{1}$, Okechukwu Ebuka Agbasi ${ }^{2 *}$, Zaidoon Taha Abdulrazzaq ${ }^{3}$, Ubong Williams Robert ${ }^{4}$ \\ ${ }^{1}$ Department of Physics, University of Uyo, Uyo \\ ${ }^{2}$ Department of Physics, Michael Okpara University of Agriculture, Umudike \\ ${ }^{3}$ Ministry of Science and Technology/Space Directorate and Communication. \\ ${ }^{4}$ Department of Physics, Akwa Ibom State University, Ikot Akpaden, Mkpat Enin \\ *Corresponding author E-mail: agbasi.okechukwu@gmail.com
}

\begin{abstract}
Thermo physical properties of Alates (Swarmers) termite wing has been investigated. The result of our investigation shows the values of thermo physical parameters of the sample materials as $0.0403 \mathrm{Wm}^{-1} \mathrm{~K}^{-1}$ being the mean thermal conductivity value, bulk density of 188 . $8 \mathrm{kgm}-3$ and thermal diffusively value being $8.2485 \times 10^{-8} \mathrm{~m}^{2} \mathrm{~s}^{-1}$. The values are within the values for commonly used insulating materials. Comparing the rate of cooling as well as heat absorption into the material as lagging material with the performance of fiberglass and cork, Alate's wing is adjudged to be a potential insulating raw material.
\end{abstract}

Keywords: Thermophysical Properties; Alates Termite; Insulation; Bulk Density; Specific Heat Capacity.

\section{Introduction}

The issue of climate change and global warming is a matter of concern the world over [1]. It has caused serious thermal discomfort to the inhabitants of the earth. Mankind is not exonerated as a causative agent, through his activities and omissions. Man's yearning for the development of human civilization, urbanization, industrialization, mineral exploration among others, has taken an alarming dimension.

The way in which man uses scientific and technological processes for the achievement of the above desires has been heterodoxical and revolutionary in nature. With this, man has acquired tools with which he can command nature and alter natural parameters and phenomena imposing human order on the environment to achieve his purpose. Yet the tools have increased his individual and collective capacity to destroy himself and his kind. Through man's activities comes climate change, hence thermal discomfort, also through man's search for possible means of thermal insulation would the thermal discomfort problem be solved.

Thermal insulation is used during the reduction of the temperature gradient from the interior in comparison with that of the exterior, notwithstanding how severe. The climate may be [2], [3]. This is so considering the fact that heat energy is not energy residing in a body but is energy in transit to and from the body.

Most of the insulation materials presently in used are synthetic products, whereas few are non-synthetic, which are mostly of plant's origin. The non-synthetics are environmental friendly than the synthetics. The non-synthetic is in addition renewable in nature. Obviously, nature has provided mankind with a great variety of useful sources of raw materials for production of material goods required for the existence, comfort and conveniences of man. Despite this, mankind seems to be in want due to unavailability of data on the usefulness, efficacy, efficiency and effectiveness of a large variety of materials provided by nature for the comfortable existence of man [4], [5], [6], [7].

The present research is on the thermophysical properties of Alates (Swarmers) termite wing. What makes this work novel is the fact that there is no report of any kind on thermophysical properties of termite wing.

Alates (Swarmers) termite are part of the caste in damp wood, dry wood and subterranean termites responsible for reproduction and dispersion of the colonies. Each has a pair of wing, oval in shape measuring about $3.5 \mathrm{~cm}$ long transparent in nature with a rib lining the upper part. About 1000 Alates leave the colony for meeting and colonizing flight each time. They cast their wings after colonizing flight turning into successive kings and queens [8].

\section{Theoretical consideration}

\subsection{Thermo physical properties}

Accurate knowledge of thermo physical properties of materials determines the accuracy of engineering calculations [9], [10], [11], [12], [13]. Putting it in another way, [14] posits that ultra large scale integrated manufacturing has thermo physical parameters as key factors. The work of [15] shows thermo physical properties to include transport and thermodynamic properties. Diffusion rate coefficient, such as thermal conductivity, $\mathrm{k}$, in case of heat transfer and the kinematic viscosity, which involves momentum, are examples of transport properties. Equilibrium state of a system 
makes for thermodynamic properties. Specific heat capacity and density are examples of thermo physical properties employed in most analysis that has to do with thermodynamical. Material's ability to store energy, for instance, denoted as volumetric heat capacity is the product of its density and the specific capacity. Materials of low density are in most cases characterized by large specific heats.

Whittington et al [16] acknowledges that even the thermal evolution of planetary crust and lithosphere is largely governed by thermophysical properties, namely; thermal conductivity, diffusively, density and specific heat capacity [17]. This is in support of the report of [18], [19], [20], [21] add thermal linear expansion to the parameters earlier named as thermophysical properties.

\subsection{Thermal conductivity}

Thermal conductivity has been scrupulously defined by several authors including [22], [23], [24], [25], [26], [27], [28] in agreement with others, expresses that heat conduction through homogeneous material, which heat is flowing only in one direction, say x-direction, having a uniform thermal conductivity has the general equation.

$$
Q=\frac{T_{\text {upper }}-T_{\text {lower }}}{x / k A}
$$

Where $x / k A=\left(R_{t h}\right)_{\text {cond }}$ is thermal resistance to heat conduction, $\mathrm{A}$ is the cross sectional area, $\mathrm{x}$ the thickness, $\mathrm{k}$ is the thermal conductivity, $\mathrm{T}_{\text {upper }}$ and $\mathrm{T}_{\text {lower }}$ the upper and the lower steady state temperature respectively.

Calsitherm[29] considered the effect of pore structure and macrostructure analysis on the thermal conductivity. According to [24] insulating solid at low temperature has low thermal conductivity due to lack of conduction electrons rather heat transport is by photons, which involves lattice vibration. Whereas, linear relationship in thermal conductivity dependent of temperature is assumed by [30] in his method of averages to determine insulation conductivity under transient conduction. This is supported by the work of [28] which asserts that the relationship is almost linear for most materials expressing it thus

$$
k=\beta k_{o} T+k_{o}
$$

Where $k_{o}$ is the thermal conductivity at $0^{\circ} \mathrm{C}$ ?

$\beta$ is the temperature coefficient of thermal conductivity

$\mathrm{T}$ is the temperature

$\mathrm{k}$ is thermal conductivity at temperature $\mathrm{T}$.

Feng et al [31] on the other hand assume statistical self-similarity existence in porous media in formulating a generalized model for the effective thermal conductivity determination of porous media. Their assumption has origin from the work of [32], [33], [34], [35], and [36].

Beck et al [37] and [38] in their contribution assert that the total thermal conductivity in highly porous insulation is the sum of the gaseous conductivity, ${ }^{g a s}$, the solid conductivity, ${ }{ }_{\text {solid }}$, radiative conductivity $k_{n d}$ and a coupling term $k_{\text {couple }}$, expressing mathematically thus

$$
k=k_{\text {gas }}+k_{\text {solid }}+k_{\text {nd }}+k_{\text {couple }}
$$

$k_{\text {couple }}$ accounts for the gas condition that short circuits the high thermal resistance thermally between the contact points between the fibers. [15] and [39] express mathematically in isotropic homogenous material where specific heat, density, thermal conductivity are assumed the same everywhere and properties are independent of surface orientation, where $k_{x}=k_{y}=k_{z} \quad(\mathrm{x}, \mathrm{y}$ and $\mathrm{z}$ being coordinates), thus

$\frac{\delta^{2} T}{\delta x^{2}}+\frac{\delta^{2} T}{\delta y^{2}}+\frac{\delta^{2} T}{\delta z^{2}}+\frac{q_{g}}{k}=\frac{\rho c}{k} \cdot \frac{\delta T}{\delta \tau}=\frac{1}{\alpha} \cdot \frac{\delta T}{\delta \tau}$

Where $\alpha=\frac{k}{\rho c}$ is the thermal diffusivity

Assuming no energy generation, the above equation reduces to

$$
\frac{d}{d x}\left(k \frac{d T}{d x}\right)=0
$$

When the heat transfer is one-dimensional in the $\mathrm{x}$ direction.

Kossecka [30] expresses the equation as a consequence of the reciprocity principle in one-dimension as

$$
-k \frac{\delta T(0)}{\delta x}+\frac{1}{L} \int_{0}^{L} \frac{\delta \zeta}{\delta x}=q(0)+\frac{1}{L}[\zeta(l)-\zeta(0)]
$$

$\mathrm{L}$ being the thickness of homogeneous plane slab surface of the slab corresponding to the plane $\mathrm{x}=0$ and $\mathrm{x}=\mathrm{L}$

$\zeta$ is the Kirchoff's potential

$\mathrm{T}$ is the temperature at the linearity region of the function $\mathrm{k}(\mathrm{T})$ $\mathrm{Q}(0)$ the heat flux at $\mathrm{x}=0$

\subsection{Thermal diffusivity}

Silva et al [17] likening thermal diffusivity to optical band energy, see it as necessary physical parameter to be considered in modeling and manufacturing devices. They express the relationship between thermal conductivity and thermal diffusivity mathematically thus,

$$
k=\alpha \rho c
$$

$\alpha$ being thermal diffusivity, $\rho$ is the bulk density of the sample, $\mathrm{c}$ is specific heat capacity of the material.

This agrees with the expression of [40]. Several researchers and authors including [10], [15], [28], [41], [42], and [43] have severally defined thermal diffusivity $\alpha$ as the ratio of thermal conductivity $\mathrm{k}$ to thermal capacity

$$
\alpha=\frac{k}{\rho c}
$$

But Diamant [44] had earlier expressed thermal diffusivity in heating up walls from cold as the ratio of thermal conductivity to the thickness and specific heat of wall layer in building and express it thus

$$
\alpha=\frac{k}{d c}
$$

And has the unit $\mathrm{m}^{2} \mathrm{~s}^{-1}$, where $\mathrm{k}$ is the average thermal conductivity of wall layer in $\mathrm{Wm}^{-1} \mathrm{~K}^{-1}, \mathrm{~d}$ is the thickness of wall layer in meters and $\mathrm{C}$ the specific heat of the wall layer in $\mathrm{JKg}^{-1} \mathrm{~K}^{-}$ ${ }^{1}$. Relating diffusivity to temperature propagation, he asserts that the higher the diffusivity, the most quickly the changes in temperature propagation. The changes is, however, said to be without much loss of amplitude. 
ThoughMinkpwyez [45] see estimation of thermal diffusivity of a solid from transient temperature measurement as one of a parameter estimation problem in heat transfer. Their assertion collaborates the position of [46], and [47], but [48], however express transient heat transport equation as being governed by thermal diffusivity in Laplacian form as earlier expressed by other authors including [42] thus

$$
\frac{\delta T}{\delta t}=\alpha \Delta^{2} T
$$

Stressing that an exact knowledge of thermal diffusivity of rock is of utmost importance for the study of the thermal regime of the Earth's crust.

US forest Products Laboratory [4] gives thermal diffusivity value of dry wood to be $0.00025 \mathrm{inch}^{2} \mathrm{~s}^{-1}$ which translates to $1.613 \times 10$ ${ }^{7} \mathrm{~m}^{2} \mathrm{~s}^{-1}$. The report does not show whether it is for hard or soft wood.

\subsection{Density}

Bulk density is very vital parameter of any insulation system and is determined by the way the material of the solid is interconnected [15]. The more the percentage of dead air space or still air volume the lower the bulk density and lower the thermal conductivity, hence the better the heat insulating ability.

\subsection{Specific heat}

According to [49] the amount of heat needed to raise the temperature of one gram of the substance by one degree Celsius or Kelvin without change in a physical state (phase) is known as specific heat. Whereas, [4] has it that, the fact that energy of absorption of wood increases as its temperature increases, increase in temperature, therefore, lead to apparent increase in specific heat.

\section{Materials and experimental methods}

Fallen wings of Alates termite were collected from the verandas of Faculty of Science, University of Uyo, main campus at Use Offot, Uyo in Akwa Ibom state, Nigeria, located at latitude $5^{0} 2^{\prime} 0^{\prime}$ ' $\mathrm{N}$ $5^{\circ} 4^{\prime} 00^{\prime \prime} \mathrm{N}$ and longitude $7^{0} 58^{\prime} 0^{\prime \prime} \mathrm{E}-8^{0} 0{ }^{\prime} 0^{\prime}{ }^{\prime} \mathrm{E}$. The collected wings were carried in a bag. It was sprayed in one of the laboratory rooms for air drying. Sieve was used to sieve out grains of sand from the dry wing sample to allow pure wings. The dry wings was subjected to grinding. The grinded sample was smeared with water to be damp and put in a pre-prepared mold measuring $0.300 \mathrm{~m} \times 0.300 \mathrm{~m} \times 0.025 \mathrm{~m}$ to prepare a sample size of that measurement, the size needed by the test equipment, the Bruel and Kjaer Rapid thermal conductivity machine, for the determination of thermal conductivity of the material.

The sample was compressed while still in the mold using compression machine and allowed to be in that position for 48 hours before it was removed from the compression machine and kept out for air drying. The dry Alates termite wing board sample was continuously subjected to weigh until a constant weight was achieved. At that point, the sample was declared dry. The procedure was repeated for 9 (nine) other board samples of Alate's termite. The prepared sample boards were used for experimental investigation. The method described elsewhere by [50] using BruelKjaer Rapid thermal conductivity machine, was used for the determination of thermal conductivity of the prepared sample boards. The equipment is a compact self-contained instrument for the determination of thermal conductivity of materials of insulation. A full and detailed description of the equipment is given elsewhere [50]. The equipment employs the steady-state method. Dry sample boards were used to avoid the problem of redistribution of water under the influence of the temperature gradient [51] and [52].

However, for purpose of completeness, the test equipment is a compact self-contained instrument for the determination of thermal conductivity of materials of insulation.

The test section comprises a stationary upper section and capable of being adjusted to accommodate various sample thickness not exceeding $0.10 \mathrm{~m}$ maximum. The upper section comprises a heat sink plate with coils separated from a controller heater and aluminum surface by insulation. This surface is often maintained at a higher temperature than the lower plate. The upper surface plate has a chromel-alumel thermocouple installed in the center to measure the temperature.

The lower section has a moveable base plate mounted on the four guide rods with ball bushing. A heat sink plate, aluminum plate and controlled heater are parts of the movable base plate. Also attached to the lower surface plate is a heat flow transducer. Chromel-alumel thermocouple is also attached to the top surface of the lower plate for the measurement of the temperature. The instrument has $39.99 \mathrm{mV}$ full-scale digital panel meter installed on the front panel where the output of the various thermocouples, and the heat flow transducer can be displayed.

In order to determine thermal conductivity of the samples, fiberglass wool used as a calibration sample was first inserted into the appropriate section through the instrument. Care was taken that the sample was firmly held between the hot and cold faces. The equipment was switched on. The test section was allowed to reach a steady state of thermal equilibrium, observing that the two controlling temperature on the front panel of the instrument remained constant without any further change irrespective of the increase in duration of the experiment. Data for heat flow meter output for the calibration sample Qc; hot surface steady state temperature $\mathrm{T}_{\mathrm{h}}$ for the calibration sample in $\mathrm{mV}$; calibration sample thickness $\mathrm{x}$; and cold surface steady state temperature Tc for the calibration sample in $\mathrm{mV}$ was read directly from the Bruel and Kjaer Rapid thermal conductivity equipment and recorded. The test sample was then placed in the instrument, and the procedure repeated and temperature at both the upper and lower sections allowed to attend constant reading as in the case of calibration sample. Corresponding data $\mathrm{Q}, \mathrm{T}_{\mathrm{h}}, \mathrm{x}$ and $\mathrm{Tc}$ for each of the test samples were also obtained. That was done for the 10 (ten) prepared Alates termite wing test sample board. Temperature differences $\Delta T_{c}=T_{h c}-T_{c c}$ and $\Delta T=T_{h}-T_{c}$ were calculated, respectively for the calibration and test samples in $\mathrm{mV}$. The relationship given by [50] as

$$
Q_{c} x_{c} \Delta T k=Q x \Delta T_{c} k_{c}
$$

$$
k=\frac{Q x \Delta T_{c} k_{c}}{Q_{c} x_{c} \Delta T}
$$

Where $\mathrm{k}$ and $\mathrm{k}_{\mathrm{c}}$ represent the thermal conductivity of the test and calibration samples respectively, was employed for the calculation of the thermal conductivity values of the test sample boards. The experiment was carried out at ambient temperature of $29^{\circ} \mathrm{C}$.

The bulk density was determined by measuring mass and volume of the sample, using weighing and displacement method as described elsewhere [51]. The conventional formula which abound in several textbook and journal as

$$
p=\frac{m}{v}
$$

Was employed for density determination, where $\rho$ designates density, $\mathrm{M}$ mass and $\mathrm{v}$ volume of the sample.

A modified calorimetric method, employing cooling correction was used for determination of specific heat capacity [51] and [53]. 
Thermal diffusively computation was done using equation 8 and the volumes of other parameters. Whereas comparison of the rate of cooling of hot water in Alate's termite wing lagged system, fiberglass wool tagged system and unlagged system was done using uniformly designed calorimeter systems having $0.09 \mathrm{~m} \mathrm{x}$ $0.105 \mathrm{~m} \times 0.063 \mathrm{~m}$ inner container with outer jacket of $0.10 \mathrm{~m} \times$ $0.115 \mathrm{~m} \times 0.073 \mathrm{~m}$, with lid in each case. Each system was filled with equal volume of hot water with thermocouple inserted and connected to temperature display meter. The three were placed under same environmental condition and the rate of cooling simultaneously monitored and recorded at the same time intervals down to about environmental temperature. The systems were thereafter emptied, washed and dried. They were subsequently filled with ice block of appropriately equal mass with the thermocouple inserted. The three were again placed under same environmental condition and the rate of heat gain simultaneously monitored and recorded at the same time intervals as in the case of hot water. Graphs of temperature against time for cooling rate and that of the rate of heat gain were plotted for Alates termite wing lagged, fiberglass wool lagged, unlagged systems and atmospheric temperature for comparison.

\section{Results}

The experimental result of the thermal conductivity measurement is as seen in Table 1, while Table 2 carries the result of thermal conductivity, bulk density, specific heat capacity and thermal diffusively calculated using the other parameters. Tables 1 and 2 show mean thermal conductivity value of $0.0403 \mathrm{Wm}^{-1} \mathrm{~K}^{-1}$ with a standard error of $0.0020 \mathrm{Wm}^{-1} \mathrm{~K}^{-1}$ at room temperature of $29^{\circ} \mathrm{C}$; mean bulk density value of $188.8 \pm 1.526 \mathrm{Kgm}^{-3}$; mean specific heat capacity of $2622.33 \pm 78.693 \mathrm{JKg}^{-1} \mathrm{~K}^{-1}$ and $8.2435 \times 10^{-8} \pm 0.516$ $\mathrm{x} 10^{-8} \mathrm{~m}^{2} \mathrm{~s}^{-1}$ being the mean thermal diffusivity value with its standard error. Figures 1 shows the results of comparative study of the rate of absorption of heat by ice block in systems lagged with fiber glass wool and Alate's termite wing sample, while figure 2 shows the result of the comparative study of cooling rate of hot water in systems lagged with fiber-glass wool and Alate's termite wing sample board.

Table 1: The Experimental Results from Bruel and Kjaer Rapid K Thermal Conductivity Machine

\begin{tabular}{|c|c|c|c|c|c|c|c|}
\hline \multicolumn{2}{|l|}{ Sample } & $x \times 10^{-2}(\mathrm{~m})$ & $\mathrm{T}_{\mathrm{h}}(\mathrm{mV})$ & $\mathrm{T}_{\mathrm{c}}(\mathrm{mV})$ & $\mathrm{Q}(\mathrm{mV})$ & $\Delta_{\mathrm{T}}(\mathrm{mV})$ & $\begin{array}{l}k \\
\left(W_{m^{-1}} K^{-1}\right)\end{array}$ \\
\hline \multicolumn{2}{|c|}{$\begin{array}{l}\text { Glass fiber (Calibration } \\
\text { Sample) }\end{array}$} & $2.51^{*}$ & $2.501^{*}$ & $2.117^{*}$ & $0.920^{*}$ & $0.384^{*}$ & $0.0350^{*}$ \\
\hline \multirow[t]{10}{*}{ Research Sample } & 1 & 2.60 & 2.614 & 2.005 & 1.483 & 0.609 & 0.0368 \\
\hline & 2 & 2.53 & 2.611 & 2.069 & 1.360 & 0.542 & 0.0370 \\
\hline & 3 & 2.49 & 2.505 & 2.125 & 0.918 & 0.380 & 0.0350 \\
\hline & 4 & 2.52 & 2.619 & 2.148 & 1.590 & 0.471 & 0.0495 \\
\hline & 5 & 2.56 & 2.510 & 2.068 & 1.063 & 0.442 & 0.0358 \\
\hline & 6 & 2.54 & 2.605 & 2.064 & 1.358 & 0.541 & 0.0371 \\
\hline & 7 & 2.50 & 2.618 & 2.190 & 1.470 & 0.428 & 0.0500 \\
\hline & 8 & 2.51 & 2.607 & 2.217 & 1.090 & 0.390 & 0.0408 \\
\hline & 9 & 2.49 & 2.610 & 2.166 & 1.170 & 0.444 & 0.0382 \\
\hline & 10 & 2.53 & 2.613 & 2.235 & 1.105 & 0.378 & 0.0431 \\
\hline Mean & & 2.53 & 2.591 & 2.129 & 1.261 & 0.463 & 0.0403 \\
\hline
\end{tabular}

* Indicates $x_{c},\left(\mathrm{~T}_{\mathrm{h}}\right)_{\mathrm{c}},\left(\mathrm{T}_{\mathrm{c}}\right)_{\mathrm{c}}, \mathrm{Q}_{\mathrm{c}}, \Delta \mathrm{T}_{\mathrm{c}}$ and $\mathrm{K}_{\mathrm{c}}$ values for calibration sample.

$\mathrm{Q}_{\mathrm{c}}$; hot surface steady state temperature $\mathrm{T}_{\mathrm{h}}$; for the calibration sample in $\mathrm{mV}$; calibration sample thickness $\mathrm{x}$; and cold surface steady state temperature $\mathrm{T}_{\mathrm{c}}$ for the calibration.

Table 2: Calculated Values for Thermal Conductivity, Bulk Density, Specific Heat Capacity and Thermal Diffusivity of Alates Wing Sample

\begin{tabular}{lllll}
\hline Sample Code & $\begin{array}{l}\text { Thermal Conductivity } \\
\left(\mathrm{Wm}^{-1} \mathrm{~K}^{-1}\right)\end{array}$ & Bulk of Density $\left(\mathrm{Kgm}^{-3}\right)$ & $\begin{array}{l}\text { Specific Heat Capacity } \\
\left(\mathrm{JKg}^{-1} \mathrm{~K}^{-1}\right)\end{array}$ & $\begin{array}{l}\text { Thermal Diffusivity } \times 10^{-8} \\
\left(\mathrm{~m}^{2} \mathrm{~s}^{-1}\right)\end{array}$ \\
\hline 1 & 0.0368 & 186.0 & 2696.3 & 7.3386 \\
2 & 0.0370 & 190.0 & 2704.0 & 7.1940 \\
3 & 0.0350 & 191.0 & 3041.5 & 6.0273 \\
4 & 0.0495 & 192.0 & 2371.5 & 10.838 \\
5 & 0.0358 & 179.0 & 2371.0 & 6.8736 \\
6 & 0.0371 & 183.0 & 2925.0 & 7.8518 \\
7 & 0.0500 & 194.0 & 2582.0 & 10.498 \\
8 & 0.0408 & 192.0 & 2455.0 & 8.8469 \\
9 & 0.0382 & 188.0 & 2771.0 & 7.3328 \\
10 & 0.0431 & 193.0 & 2306.0 & 9.6841 \\
Mean & 0.0403 & 188.8 & 2622.33 & 8.2485 \\
SE & \pm 0.002 & \pm 1.526 & \pm 78.693 & \pm 0.516 \\
\hline
\end{tabular}




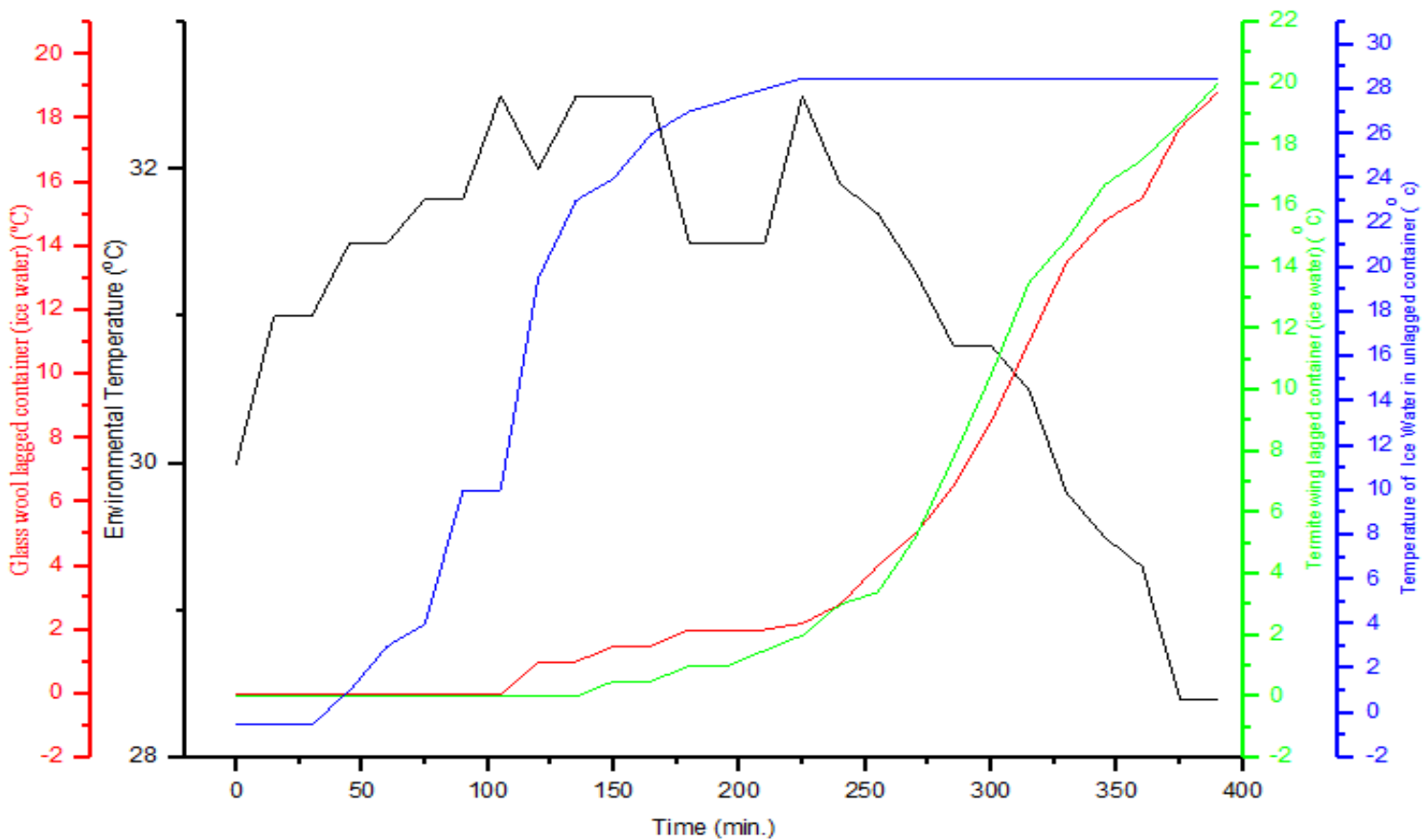

Fig. 1: Rate of Heat Gain by Ice Block in System Lagged with Fiber Glass Wool, Alates Termite Wing, and Unlagged System.

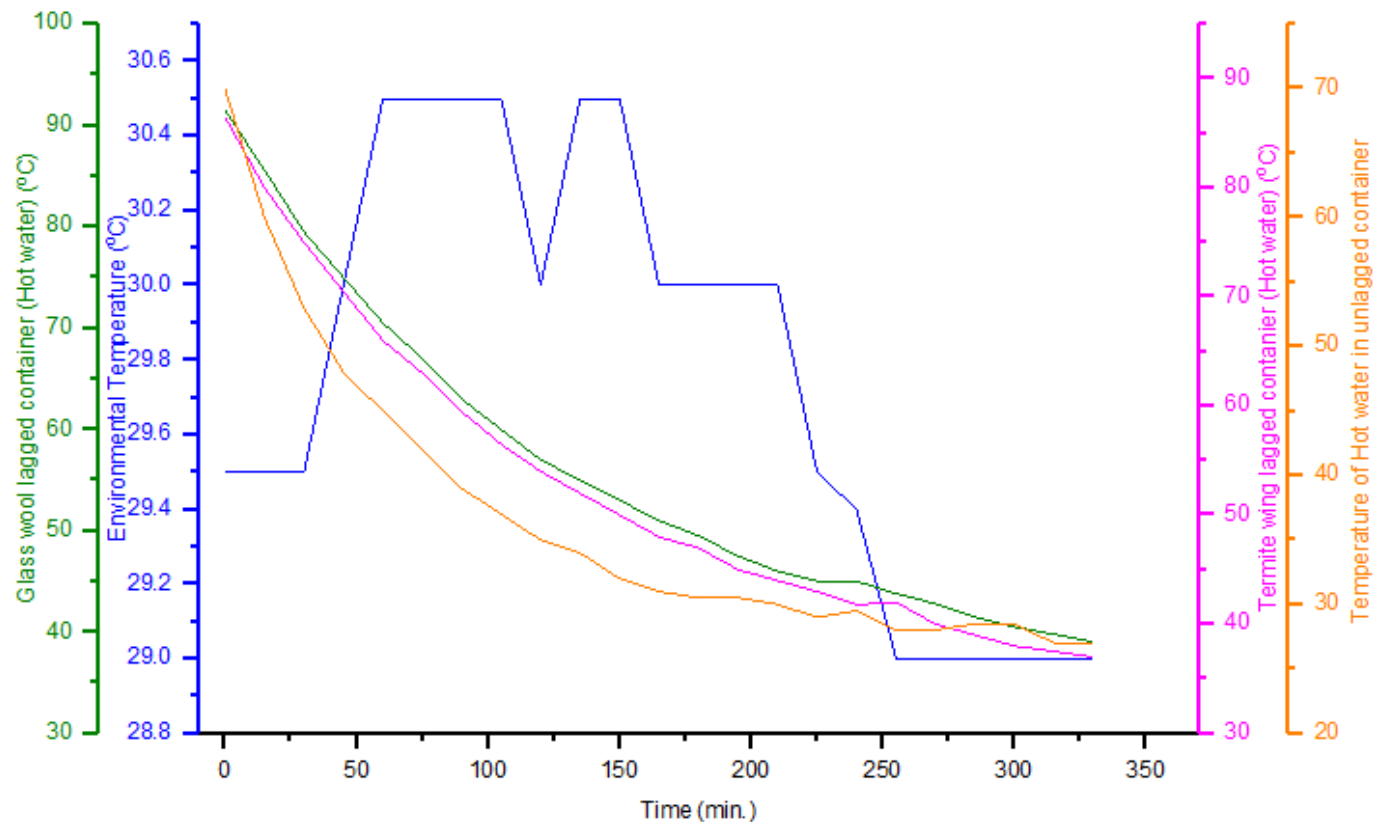

Fig. 2: Rate of Heat Lose by Hot Water in System Lagged with Fiber Glass Wool, Alates Termite Wing, and Unlagged System.

\section{Discussion}

The mean thermal conductivity value of our sample board, Alates termite wing sample board is $0.0403 \mathrm{Wm}-1 \mathrm{~K}-1$ which is very close to the values of most of the already established thermal insulators such as fiber-glass wool, which is reported to be between $0.0332-0.0404 \mathrm{Wm}^{-1} \mathrm{~K}^{-1}$, Air felt $0.0389 \mathrm{Wm}^{-1} \mathrm{~K}^{-1}$, Granulated Cork $0.0476 \mathrm{Wm}^{-1} \mathrm{~K}^{-1}$ and Re-granulated cork particles $0.474 \mathrm{~cm}$ with $0.04471 \mathrm{Wm}^{-1} \mathrm{~K}^{-1}$, Polyurethane foam (rigid) 0.0245 $\mathrm{Wm}^{-1} \mathrm{~K}^{-1}$ given by [54]. This suggests that the termite wing board has a high percentage of still air space, which inhibits a thermal conduction process among others. With this result, the wing of Alate's termite wing is within the range of good thermal insulating materials. It is therefore, not wrong to suggest that our research sample, Alatest termite wing, is a potential raw material for thermal insulator. This is highly supported by its bulk density value, the specific heat capacity of the termite wing board is equally supportive of our earlier claim.
More so, comparing the value of thermal diffusively of our sample material with the value given for dry wood by the [4] as $0.00025 \mathrm{inch}^{2} / \mathrm{s}(1.613 \times 10-7 \mathrm{~m} 2 \mathrm{~s}-1)$,), the value for our sample material is less than that of dry wood, meaning that Alate's termite wing board would slow down the rate of temperature change to a system that is lagged with it. This implies that response to temperature change by the sample is quite low. It figures 1 and 2 confirm that the sample response very slowly to temperature change, hence demonstrating a very slow rate heat will diffuse through it.

For instance, Figure 1 shows that ice water in the unlagged system gains heat and attains a temperature almost at the level of that of the atmospheric environment within a short time of about $150 \mathrm{~min}$, whereas that of the container lagged with our research sample together with that of fiberglass wool was at temperature of about $8^{\circ} \mathrm{C}$ at $300 \mathrm{~min}$ and about $20^{\circ} \mathrm{C}$ at $400 \mathrm{~min}$. The rate of heat again as shown in the figure is approximately the same for both the Alatest termite wing lagged system, and the fiberglass wool lagged system. Comparison of the plots in Figure 2 also reveals that the 
rate of heat lost by hot water in the two lagged containers is slow and is approximately the same for both Alatest termite wings lagged system and fiberglass wool lagged system. This collaborates with the earlier observation, showing our research sample to be in the class of fiberglass wool as a good thermal insulator.

One other advantage of Alate's termite wing board as a thermal insulator over fiberglass, foam and asbestos is that wing of Alate's termite is environmental friendly. It is not likely to pose any health hazard as may be experienced by others. It is from a renewable source and presently not put to any useful purpose.

\section{Conclusion}

In conclusion, it is reasonable after comparison of the thermo physical properties of our research sample with those of the commonly known and used thermal insulating materials to adjudge that Alate's termite wing is among the group of good thermal insulating materials. This is one material that is renewable in nature with high sustainability yet to be tapped for useful purposes.

\section{Recommendation}

We recommend that the wing of Alates (Swarmers) be used as raw materials for the production of the insulation board for thermal insulating systems such as food flask and coolers, cold room as well as ceiling materials for dwelling houses. It would be a very cost effective measure in reducing fossil-fuel energy demand. It is, however, not recommended for systems with very high temperature like oven and furnace.

\section{References}

[1] The Economist (2015). Clear Thinking on Climate Change November 28th - December 4th edition, volume, 417, number 8966, the Economist Newspaper ltd, London, pp 13, 14.

[2] Al-Sanea S.A, Zedan, M.F., Al-Ajlan S.A., Abdul Habi, A.S (2003). Heat Transfer Characteristics and Optimum Insulation Thickness for Cavity Walls. Journal of Thermal Env. And Bldg. Sci., Vol. 26, No.3 pp. 285 - 307. https://doi.org/10.1177/109719603027973

[3] AL- Momoud M. S. (2004). The Effectiveness of Thermal Insulation in Different types of buildings in Hot Climates. Journal of Thermal Env. and Bldg. Sci 27(3): 235- 247. https://doi.org/10.1177/1097196304038368.

[4] United States of America Forest Products Laboratory Wood Handbook (1974) Wood as an Engineering Material. Us Government Printing Office, Washington, USA.

[5] Etukudo, I. E., (2000). Forest our Divine Treasure. Dorand Publisher, Uyo Nigeria.

[6] Etukudo, I. E, (2003) Enthnobotany Conventional and Traditional Uses of Plants vol.1, verdict press Uyo Nigeria.

[7] Null G. (2004). The Complete Encyclopedia of Natural Healing Bottom Line Books, Stanford. Conn. USA

[8] Schneider, M. F. (1999). General Information about Termite (2). Termite Life Cycle and Caste System. http://www.fzifreiburg.de/insectpestkey-long\%20version/termit2.htm.

[9] Senger, J. V., and Klein M. (1980). The Technical Importance of Accurate Thermophysical Property Information. National Bureau of standards Technical Note No. 590.

[10] Naijar, M. S., Bell, K. J., and Maddox R. N. (1981). Heat Transfer Eng. 2, 27. https://doi.org/10.1080/01457638108962758.

[11] Adeosun B. F. and Olaofe O. (2002). Thermodynamic Parameter of Stretching and Thermal Conductivity of Loaded Natural Rubber. J. Chem. Soc. Of Nigeria 27 (2):128.

[12] Fontana, A. J., Wacker, B., Campbell C. S. and Campbell G. S (2001). Simultaneous Thermal Conductivity, Thermal Resistivity and Thermal Diffusivity Measurement of Selected Foods and Soils. The society for engineering in agricultural food and biology systems. An ASAE meeting presentation paper number: 01-6101.
[13] Polley S. L., Snyder, O. P. and Kotnour, P. (1980). A Compillation of Thermal Properties of Foods. Food Technology. 34(11):76-94.

[14] Ekpe S. D. (2005). Study of Energy Flux in Magnetron Sputter Deposition system. A thesis submitted to the faculty of Graduate studies and Research in partial fulfillment of the requirements for the degree of Doctor of philosophy, Department of Electrical and Computer Engineering, University of Alberta, Edmonton, Canada. pp 54, 55.

[15] Incropera F. P. and De Witt D. P. (1990). Fundamentals of Heat and Mass Transfer 3rd Edu, john Wiley and Sons, New York, pp 43 -66 .

[16] Whittington, A. G., Hofmeister A. M and Nabelek P. I. (2009). Temperature - dependent thermal diffusivity of the Earth's Crust and implications for magmation. Nature, 458, pp 319- 321. https://doi.org/10.1038/nature07818.

[17] Silva T. S., Alves, A. S, Pepe, I., Tsuzuki, H., Nakamuna, O., D'AngularNeto M. M. F., Ferreira da Silva, A., Velssid, N., and An, C. Y. (1998). Thermal Diffusivity of Lead Lodide Journal of Applied Physics, 83 (11): 6193-6195.

[18] Petitijean, S. Rabinowicz M., Gregoire M. and Chevrot, S. (2006). Difference between Archean and Proterozoic lithospheres: Assessment of the possible major role of thermal conductivity. Geochem. Geophys. Geosyst 7, https://doi.org/10.1029/2005GC001053.

[19] Turcotte, D. L. and Schubert G. (2001). Geodynamics, 2nd Edu, Cambridge University Press pp 132-194.

[20] Thompson W. (1899). The age of the Earth as an abode fitted for life science 9:665-674.

[21] Touloukian Y. S. and Ho C. Y. (1970 - 1977). Thermophysical Properties of Matter, the TPRC. Data Series, plenum press, New York, volumes 1-13.

[22] Fink D. G. and Mckenzie (1975). Electronics Engineer's Handbook, McGraw - Hill, New York 6-10.

[23] Pritchard, R. T. (1970). General Course Workshop Processes and Materials, Hodder and Stoughton, London, 17.

[24] Reif R. (1965). Fundamentals of Statistical and Thermal Physics. McGraw - Hill, New York, 482-483.

[25] Wolfson R. and Pasachoff J. M. (1999) Physics, 3rdEdn. Volume One. Addison- Wesley New York, 481.

[26] Tippler, P. A. and Mosca, G. (2004). Physics for Scientists and Engineers, vol.1, 5th Edu, W.H. Freeman, USA, $634-635$.

[27] Young H. D., Freeman R. A. and Ford A. L. (2008). University Physics with Modern Physics, Pearson International Edu. 12thEdn. Pearson Addison - Wesley New York, 592, 593.

[28] Rajput, Er. R. K. (2015). Heat and Mass Transfer, Revised Edn. S Chand and Company PVT 1td, Ram Nagar, New Delhi pp 13-45.

[29] Calsitherm (2002). Calcium Silicate Products for Insulation and Engineered Applications. Ceramic News Special Refractories.

[30] Kossecka, E. (1999). Method of Average to Determine Insulation Conductivity under Transient Conditions. J. Thermal Env and Bldg SC. 23: 145 - 158. https://doi.org/10.1177/109719639902300204.

[31] Feng, Y., Yu B., Zou, M. and Zhang, D. (2004). A Generalized Model for the Effective Thermal Conductivity of Porous Media Based on Self-similarity. J. Phys. D: Applied phys. 37:3030-3040. https://doi.org/10.1088/0022-3727/37/21/014.

[32] Krupiczka R. (1967). Analysis of Thermal Conductivity in Granular Materials Int. Chem. Engr, 7:122.

[33] Hsu C. T., Cheng P. and Wong K. W. (1995). A Lumped-parameter Model for Stagnant Thermal Conductivity of Spatially Periodic Porous Media. J Heat Transfer, 117:264. https://doi.org/10.1115/1.2822515.

[34] Zehnder, P. and Schlunder E. U. (1970). Thermal Conductivity of Granular Materials at Moderate Temperatures. Chemieingr. - Tech, 42:933.

[35] Yu B. M. and Cheng P. (2002). Fractal Models for the Effective Thermal Conductivity of $\mathrm{Bi}$ - dispersed Porous Media J. Thermophys. Heat Transfer 16:22. https://doi.org/10.2514/2.6669.

[36] Ma, Y. T., Yu, B. M., Zhang, D. M. and Zou M.Q. (2003). A Selfsimilarity Model for Effective Thermal Conductivity of Porous Media. J. Phys. D; Appl.phys.36:2157. https://doi.org/10.1088/0022-3727/36/17/321.

[37] Beck, A., Heinemann, U., Reindinger, M., and Fricke. J., (2004) Thermal Transport in Straw Insulation. Journal of thermal Env. $\begin{array}{lll}\text { And } \quad \text { Bldg. } & \text { sci } & \text { 27(3):227. }\end{array}$ https://doi.org/10.1177/1097196304039831. 
[38] Frieke J. (1993). Materials Research for the Optimization of Thermal Insulation. High Temperature High Pressure 25(4): 379390.

[39] Sodha, M. S., Goyal, I. C., Tiwari, G. N. and Seth, A. K. (1977) Periodic Heat Transfer with Temperature Dependent Thermal Conductivity. Int. J. Heat Mass Transfer, 22(1): 777-781.

[40] Szelagowski, H., Arvanitidis, I. and Seetharaman, S. (1999) Effective Thermal Conductivity of Porous Strontium Oxide and Strontium Carbonate Samples. Journal of applied physics 85(1): 193-198. https://doi.org/10.1063/1.369468.

[41] Li, B. and Zhang, S. (1977). The Effect of Interface Resistance on Thermal Wave Propagation in Multi - Layered Samples. J.phys. D: Appl. Phys. (30) pp 1447 - 1454.

[42] Welty, J. R., Wick, C. E., Wilson R. E. and Rorrer, G. (2002) Fundamentals of Momentum, Heat, and Mass Transfer 4thEdn. John Wiley and Sons, Inc.

[43] Liebe, J. D., Kang H., Haupt, L., Mandal, P., Medvedeva I. V., Rao, G. H. and Barna (1998). Heat Diffusivity of Nd1-xSrxMnO3-5 and La1-xCaxMnO3-5 compounds. Journal of Applied Physics 83(11): 7148-7150. https://doi.org/10.1063/1.367790.

[44] Diamant, R. M. E., (1986). Thermal and Acoustic Insulation, Butterworth's, London.

[45] Minkowyez, W. J., Sparrow, E. M., Schneider G. E. and Pletcher R. H. (1988). Handbook of Numerical Heat Transfer, John Wiley and sons, Inc., New York, p788.

[46] Beck, J. V. and Arnold K. J. (1977). Parameter Estimation in Engineering and Science, Wiley, New York.

[47] Bard, Y. (1974). Nonlinear Parameter Estimation Academic, New York.

[48] Mottaghy D., Vosteen H. D. and Schellschmidt R. (2007) Temperature Dependence of the Relationship of Thermal Diffusivity versus Thermal Conductivity for Crystalline Rocks. Int. J. Earth Sic (GeolRundsch) Springer, D01 10.1007/s00531-0070238-3.

[49] Whitten K., Davis, R., Peck M. L. and Stanley G. (2010) Chemistry the Core, 9thEdn. Brooks Cengage Learning Mason, pp36, 37.

[50] Ajibola, K. and Onabanjo, B. (1995) Investigation of CocosNucifera as a Potential Insulator for Buildings. Renewable Energy, 6 (1). 81- 84. https://doi.org/10.1016/0960-1481(94)000322 .

[51] Ekpe S. D. and Akpabio G. T. (1994). Comparison of the Thermal Properties of Soil Samples for a Passively Cooled Building Design. Turkish Journal of Physics, 18(2): 117- 122.

[52] Jackson R. D and Taylor S. A. (1965). Heat Transfer, Methods of Soil Analysis Agronomy Monograph (1) Academic Press, pp 349 360.

[53] Tyler F. A. (1971). Laboratory Manual of Physics. 4thedn. Landon. Edward Arnold, pp 118, 119

[54] Sayigh A. A. M. (1978). Effect of Dust on Flat Plate in Proceedings of the International Solar Energy Congress, New Delhi, pp $960-$ 964. 